\title{
A ESCRITA COMO REVELAÇÃO DO 'EU'
}

\author{
WRITING AS A REVELATION OF THE 'SELF'
}

\author{
Isabel Roboredo Seara* \\ Universidade Aberta, Lisboa, Portugal
}

Resumo: No primeiro momento, passar-se-ão em revista alguns traços caracterizadores da escrita intimista, da exigência temporal ao processo de narraçã̃o retrospectiva, do fragmentarismo à descontinuidade, da ambiç̄oo recapitulativa ao risco do esquecimento. Em seguida, numa perspectiva pragmática, focalizaremos no ato de confidência desenhado, por excelência, no espaço de escrita autobiográfica. Esse ato, que estabelece a revelacçõo do eu, visa e proclama concomitantemente a partitha comunicativa. A partir da análise dos vários textos representativos dos géneros textuais, mostraremos as marcas discursivas que caracterizam esta enunciação intimista e fragmentada, por um lado, e dialógica, por outro, conduindo da permeabilidade, da porosidade destes processos e evidenciando a dimensão compósita destas próticas de escrita.

Palavras-chave: escrita; autobiografia; análise pragmática; confidênncia; dialogismo.

\begin{abstract}
To begin with, we are going to focus on some characteristic traits of intimate writing, on the temporal demands of retrospective narration, from the fragmentary to the discontinuous, from the ambition of revisiting the past, to the risk of forgetting. We will then, according to a pragmatic perspective, focus our attention on the act of confiding, specifically enclosed within the space of autobiographical writing. This act, which provides a revelation of the self, both seeks and sustains a communicative sharing. By analyzing different texts, which represent the different textual genres, we intend to show the discursive signs which are characteristic of this form of expression, which is on the one hand, intimate and fragmented on the one hand, while dialogic on the other hand; resulting from the permeability, the porosity of these processes and revealing the composite dimension of this writing practice.
\end{abstract}

Keywords: Writing; Autobiography; Pragmatic Analysis; Confidence; Dialogism.

* Professora doutora da Universidade Aberta - UAb, Lisboa, Portugal; irseara@gmail.com 
Linha D'Água (Online), São Paulo, v. 31, n. 1, p. 73-89, jan.-abril 2018

Écrire - quel qu'en soit l'objet - c'est obligatoirement s'engager dans un dialogue, et même dans de multiples dialogues, quelques que soient la sincérité et l'urgence de ce qui demande à s'exprimer . (...) Car se dire, c'est se présenter tel qu'on veut, prétend, souhaite, être lu et compris.

(Goulet 199: 7)

\section{Os escritos do 'eu' e a confidência}

Há recantos do ser e da vida que precisam do silêncio.

(Miguel Torga, Diário III)

Convocamos, ab initio, uma citação de Clara Crabbé Rocha que, há uma quinzena de anos, pressagiava já a importância de reflectir sobre a escrita intimista, que a investigadora designa « escrita do eu ». Afirma a autora:

A escrita do eu pode ser encarada como uma forma de salvação individual num mundo que começa a descrer de sucessivos modelos ideológicos de salvação colectiva. E para muitos a vivência da intimidade é uma garantia da autenticidade num tempo em que a vida pública se tornou uma espécie de « teatro do mundo ${ }^{1}$.

Esta mesma ideia surgira, em 1979, na obra «Les Tyrannies de l'intimité », de Richard Senett, sociólogo americano que prognosticava esta tendência para o desenvolvimento de uma personalidade-refúgio que apelidou de « tirania da intimidade » que se revela no exagero da confidência²:

Le moi de chaque individu est devenu son principal fardeau. Se connaître soi-même est devenu un but, une fin en soi, au lieu dêtre un moyen de connaitre le monde. ${ }^{3}$

1 ROCHA, C. 1992, p. 19.

2 Para perceber as razões histórico-sociais que presidem a esta mudança, leia-se o artigo de Girad, 1976.

3 SENNET, 1979, p. 12. 
Linha D'Água (Online), São Paulo, v. 31, n. 1, p. 73-89, jan.-abril 2018

Partimos do mito de Narciso e dos dois motivos que o configuram, para passar em revista algumas modalidades desta escrita íntima. Segundo Gerárd Genette, em Figures (1972), o mito de Narciso encerra dois motivos que parecem ambíguos e distantes: o do reflexo e o da fuga. Narciso, ao contemplar a sua imagem refletida na água sobre a qual se inclina, apaixona-se pela sua imagem que é simultaneamente a figura e o seu desdobramento: o eu que olha e o que é olhado, o sujeito e o objeto do desejo. Narciso tem uma visão idealizante de sua imagem e fica dela prisioneiro. A imagem é, ao mesmo tempo, ele próprio e a sua reprodução, tal como na escrita intimista, onde a dupla 'corpo e letra' mantêm uma relação similar. ${ }^{4}$

O outro motivo, que subjaz a este mito, é o da fuga. A imagem na água oscila, é móvel, é fugidia, tal como a linguagem é um espelho traiçoeiro. E essa projecção narcísica deseja, por um lado, fugir, seduzida pelo caudal das palavras, e, por outro, em contraste, reclama a cristalização, metáfora aqui do desejo transversal de eternização pela escrita. Também na narrativa mítica surge esta forma de cristalização quando se explicita que, no lugar onde o jovem morre, os deuses fazem nascer uma flor.

Desdobramento do sujeito, condição ilusória da imagem, mobilidade do reflexo, desejo de fixação e eternização da figura reflectida são, pois, os principais motivos do mito de Narciso, tantas vezes evocado a propósito da escrita autobiográfica. ${ }^{5}$

\section{Escrita íntima: "barómetro da alma" 6}

A etimologia de íntimo remete para o latim intimus, superlativo de interior, o que indicia que íntimo é o que está no mais profundo, que é mais interior que o próprio interior. Quando Santo Agostinho nas Confissóes interpela Deus, enuncia, talvez

\footnotetext{
4 ROCHA, 1992, p. 50-51.

5 ROCHA, p. 51.

6 PACHET, 1990. O título desta obra retoma uma metáfora célebre de Jean-Jacques Rousseau em que se alude a esta exterioridade e a esta inconstância da escrita íntima e em que este afirma: "J'appliquerai le baromètre à mon âme, et ces opérations bien dirigées et longtemps répétées me pourraient fournir des résultats aussi sûrs que [ceux des physiciens]. Mais je n'étends pas jusque-là mon entreprise. Jean-Jacques Rousseau, Rêveries du promeneur solitaire, Première promenade, 1782 - publicação póstuma.
} 
Linha D'Água (Online), São Paulo, v. 31, n. 1, p. 73-89, jan.-abril 2018

de forma pioneira, este aparente contra-senso: tu autem eras interior intimo meo, ou seja, "procuro-Vos no exterior de mim e afinal Vós estais no que tenho de mais interior e profundo" (Livro III, 11). Associa-se frequentemente a escrita intimista à ideia de instrumento de aperfeiçoamento moral, definindo-se como escrita através da qual se manifesta uma preocupação quotidiana da alma, de enfrentar a sucessão dos dias, numa perspectiva de melhorar e ultrapassar as suas insuficiências e vicissitudes, decorrentes da imprevisibilidade do tempo. E assim, à semelhança dos Exercícios Espirituais de Santo Inácio de Loyola ou d'As meditações de Fénelon, a reflexão intimista sublinha o desejo e o esforço de dominar a temporalidade, pela narração dos factos que testemunha ou dos pensamentos que se lhe acercam. Daqui decorrem duas ideias que são frequentemente apontadas e que alicerçam a escrita do "eu": por um lado, que o eu é inconsistente e inconstante e, por outro, o desejo premente de inscrever a análise do eu na ordem do dia.

Há, pois, uma panóplia de formas de escrita intimista. Textos escritos na primeira pessoa podem ser narrativos ou discursivos, continuados ou fragmentados, centrados nas ações do narrador ou no próprio ser e, malgrado as divergências, serão sempre glorificados como santuários interiores, relicários. Correspondem, no fundo, ao desejo secreto e sagrado de escrever para si, sobre si, embora esta questão coloque também alguns embaraços: basta atermo-nos nas distintas possibilidades de antonímia, para nos surpreenderem essas variações semânticas: o que não é íntimo pode ser superficial e, neste caso, 'íntimo' designaria a vontade de se conhecer melhor; por seu turno, opõe-se naturalmente a 'público' e, nesse sentido, 'íntimo' remete para o carácter privado, confidencial de um texto que, à partida, não é destinado a publicação (sabemos bem quando distantes estamos desta utopia inicial!). Íntimo, porque deve escapar às indiscrições do outro? Corresponderá a escrita intimista a uma propensão empática do autor a celebrar o seu próprio eu?

Maurice Blanchot sintetizou nesta curiosa imagem:

L'écriture intime n'est qu'une "rumination" ayant pour enjeu de sauver son petit moi $[\ldots]$ ou sauver son grand moi en lui donnant de l'air. ${ }^{7}$

7 BLANCHOT, 1986, p. 256. 
Linha D'Água (Online), São Paulo, v. 31, n. 1, p. 73-89, jan.-abril 2018

Esta escrita intimista foi, a partir dos anos 70, objecto de investigação e dois dos exegetas que procuraram, em sucessivos e numerosos trabalhos, recensear e teorizar sobre este tipo de escrita íntima que proliferou enormemente no século XX: Jean Starobinski e Philippe Lejeune. Nas últimas décadas, destacam-se na investigação Françoise Simonet-Tenant, no panorama francês e John Sturrock, na escola americana.

Eis algumas das modalidades desta escrita:

\begin{tabular}{|c|c|c|c|c|c|}
\hline Especificidades & Diário & Blogue & Autobiografia & Carta & Memórias \\
\hline Narrativa retrospectiva de vida, em prosa & $\mathrm{x}$ & $\mathrm{x}$ & $\mathrm{x}$ & $\mathrm{x}$ & $\mathrm{x}$ \\
\hline Texto fragmentário & $\mathrm{x}$ & $\mathrm{x}$ & $\mathrm{x}$ & $\mathrm{x}$ & - \\
\hline Discurso datado & $\mathrm{x}$ & $\mathrm{x}$ & $\mathrm{x}$ & $\mathrm{x}$ & $\mathrm{X}$ \\
\hline Unicidade da existência física & $\mathrm{x}$ & ? & $\mathrm{x}$ & $\mathrm{x}$ & $\mathrm{X}$ \\
\hline A existência e a vida individual, como temas & $\mathrm{x}$ & $\mathrm{x}$ & $\mathrm{x}$ & $\mathrm{x}$ & $\mathrm{X}$ \\
\hline $\begin{array}{l}\text { Assumpção do autor como entidade real e } \\
\text { narrador }\end{array}$ & $\mathrm{x}$ & $\mathrm{x}$ & $\mathrm{x}$ & $\mathrm{x}$ & $\mathrm{X}$ \\
\hline Identidade do narrador principal e do autor & $\mathrm{x}$ & $\mathrm{x}$ & $\mathrm{x}$ & $\mathrm{x}$ & $\mathrm{X}$ \\
\hline $\begin{array}{l}\text { Gesto voluntário de dizer-se, de partilhar o seu } \\
\text { quotidiano }\end{array}$ & $\mathrm{x}$ & $\mathrm{x}$ & $\mathrm{x}$ & $\mathrm{x}$ & $\mathrm{X}$ \\
\hline $\mathrm{Ab}$ initio, escrito na intimidade & $\mathrm{x}$ & $\mathrm{x}$ & $\mathrm{x}$ & $\mathrm{x}$ & $\mathrm{X}$ \\
\hline Não destinado à publicação & $\mathrm{x} /-$ & - & - & $\mathrm{x}$ & - \\
\hline Evidencia tensão público/privado & $\mathrm{x}$ & - & $\mathrm{x}$ & $\mathrm{x}$ & $\mathrm{X}$ \\
\hline $\begin{array}{l}\text { Perpetua factos, evitando os perigos do esqueci- } \\
\text { mento e os enganos da inexactidão }\end{array}$ & $\mathrm{x}$ & $\mathrm{x}$ & $\mathrm{x}$ & $\mathrm{x}$ & $\mathrm{X}$ \\
\hline $\begin{array}{l}\text { Logo que encerrado, as palavras permanecerão } \\
\text { ciosamente no silêncio }\end{array}$ & $\mathrm{x}$ & - & $\mathrm{x}$ & $\mathrm{x}$ & $\mathrm{X}$ \\
\hline $\begin{array}{l}\text { Marcas de enunciação : } \\
\text { Predomínio da primeira pessoa } \\
\text { Omissão repetida do sujeito } \\
\text { Sequências confessionais }\end{array}$ & $\begin{array}{l}\mathrm{x} \\
\mathrm{x} \\
\mathrm{x}\end{array}$ & $\begin{array}{l}\mathrm{x} \\
\mathrm{x} \\
\mathrm{x}\end{array}$ & & & \\
\hline $\begin{array}{l}\text { Topoi } \\
\text { ambição recapitulativa (Simonet-Tenant } 2001: 21 \text { ) } \\
\text { sigilo } \\
\text { O discurso da confidência: a indecisão entre a } \\
\text { vontade de escrever e de guardar segredo }\end{array}$ & $\begin{array}{l}x \\
X \\
x\end{array}$ & $\begin{array}{l}x \\
- \\
-\end{array}$ & $\begin{array}{l}- \\
\mathrm{x}\end{array}$ & $\begin{array}{l}\mathrm{x} \\
\mathrm{x} \\
\mathrm{x}\end{array}$ & $\begin{array}{l}x \\
- \\
-\end{array}$ \\
\hline
\end{tabular}


Linha D'Água (Online), São Paulo, v. 31, n. 1, p. 73-89, jan.-abril 2018

\section{Traços caracterizadores da escrita íntima}

Em primeiro lugar, este gesto de escrita nasce de uma situação de isolamento. $\mathrm{O}$ autor cria uma prisão, isolando-se dos demais e refugiando-se na sua prática redaccional, cultiva um refúgio matricial e persegue a utopia da verdade e da sinceridade na procura do que, numa forma lapidar, é expresso por Gusdorf "1 exigence d'une mise au net du dedans" ${ }^{8}$. Decorre de uma necessidade de comunicação do eu consigo mesmo ou com os outros, daí a função terapêutica que encerra.

Textos que são o refúgio, o lugar privilegiado do segredo, mas que paradoxalmente se constituem como género aberto ao outro e em que a presença do outro é valorizada mais pelo olhar do que pela sua tematização: o olhar do outro que pode aniquilar ou estimular.

É interessante recensear a história desta prática e cotejá-la com os exercícios espirituais de fortes raízes cristãs. Os escritos íntimos constituem uma espécie de exercício moral. Constatamos que são tributários, na sua origem e pelo seu funcionamento, do exame de consciência e de toda uma técnica reflexiva, de cariz espiritual, que o cristianismo desenvolveu'

A tradição judaico-cristã incute atitudes de recolhimento, aconselha a prática da confissão, preconiza a disciplina do exame de consciência, promove o hábito quotidiano da oração como rotina salvadora, assentes na crença da pessoa humana como ser dividido e auto-judicativo. ${ }^{10} \mathrm{E}$, se remontarmos aos primórdios do género, perceberemos a importância da confissão e da humildade que esta supostamente encerra. A escrita confessional foi, na sua essência, uma escrita religiosa, com uma função ascética e vários foram os santos, os pensadores cristãos e os místicos que a cultivaram. ${ }^{11} \mathrm{E}$ se nestas narrativas confessionais o interlocutor era inicialmente Deus, ou o seu representante terreno de quem se esperava a absolvição, com a evolução do género o próprio sujeito da enunciação ou os outros homens tornaram-se também destinatários destes escritos confessionais. Para além do pendor reflexivo

8 GUSDORF, 1991, p. 73.

9 DIDIER, 1991.

10 IDIDIER, p. 31

11 Lembrar aqui a importância das Confissões de Santo Agostinho. 
Linha D'Água (Online), São Paulo, v. 31, n. 1, p. 73-89, jan.-abril 2018

e de catarse, podem conviver duas atitudes dicotómicas: por um lado, a contrição que se desenha na humildade do reconhecimento do erro e no arrependimento e, por outro, ao invés, a exibição, sublinhada na ousadia da transgressão das regras de Deus ou do mundo. Esta escrita intimista pressupõe, naturalmente, este desejo de autognose e este isolamento.

Textos de confidência e de confissão, os escritos intimistas assumem papéis com forte marca cristã. Ao fim do dia, sobretudo à noite, é o momento do exame de consciência. A formação cristã ensina, desde cedo, às crianças, a não adormecer sem fazer essa reflexão, redimir-se dos seus pecados e pedir perdão. E mesmo que em adulto, tenha renunciado a esta crença, resta-lhe a disciplina. Daí que a escrita intimista se desenrole sobretudo à noite (mesmo na escrita de blogues) e se reclame como tempo de confissão e de redenção, conferindo à escrita essa virtude de absolvição e purificação que tantos the atribuem e enaltecem. Embora laicizados os exames de consciência, estes escritos possuem igualmente uma estrutura similar à da oração: acto de contrição pelas faltas cometidas, exame rigoroso e complacente. ${ }^{12}$

Outra das características é a descontinuidade, a construção fragmentada e sempre reiniciada. "Quando o tempo é transcrito numa folha branca, parece menos irremediavelmente perdido"13. É a denominada "narração intercalada”, ou intermitente, sintetizada aquando da caracterização do género "diário" em que se registam entre outras características relevantes a tendência para o confessionalismo, o peculiar posicionamento e configuração do destinatário, sobrevalorizando, contudo, a fragmentação diegética imposta pelo ritmo da enunciação narrativa. ${ }^{14}$

A vulnerabilidade é outra das características destes textos. Se pensarmos, por exemplo, nos diários como um dos subgéneros deste tipo de escritos, facilmente concluiremos que a justificação extrema desta vulnerabilidade é evidentemente a sua fácil destruição.

Outra especificidade que importa realçar é o domínio absoluto dos actos da confissão e da confidência como estruturantes destes escritos. São, pois, confidentes mudos. Então, pensar-se-ia que existe permissão para escrever tudo, sem

12 DIDIER, p. 56.

13 DIDIER, p. 18

14 Cf. a este propósito a entrada "Diário" em REIS; LOPES, p. 105-107. 
Linha D'Água (Online), São Paulo, v. 31, n. 1, p. 73-89, jan.-abril 2018

constrangimentos, mas, na verdade, os temas tabus, chocantes, têm as mesmas repercussões do que nos outros escritos. $\mathrm{Na}$ confidência, a relação entre o eu e a escrita define-se pela contradição entre a vontade de falar e a de guardar segredo. ${ }^{15}$

A intenção que subjaz à escrita remete inicialmente para um desdobramento, em que o "eu que escreve se distancia do eu, objeto da enunciação narrativa: "a vida reclusa na escrita”, de que nos fala Gusdorf, institui uma décalage: "un décalage continuel de l'actualité du vécu à un autre vécu fictif qui prend forme selon les vicissitudes de l'aventure scripturaire”.

Em suma, a predominância da primeira pessoa, a utilização prioritária do tempo do discurso, a omissão repetida do sujeito desenha-se como elementos configuradores dos escritos intimistas que se fixam na crença do eu, no desejo de o conhecer, de o cultivar, de o consignar no papel $^{16}$, e se fundam na relação intrínseca com a intimidade, pensada esta no seu carácter ontológico. São, pois, lugares onde se escreve a solidão, sentida não como uma falta, mas como um refúgio ${ }^{17}$. Organizam-se em volta do eu obsédant ${ }^{18}$ que sublinha perpetuamente que o texto só tem existência quando referido ao seu autor, invadindo toda a superfície textual.

\section{A confidência}

A confidência pressupõe, segundo Maria Helena Carreira (2007) que exista, por um lado, "uma verdade escondida" que é confiada a um interlocutor privilegiado e, por outro, que este assuma o papel de confidente, ou seja, que torne possível a confidência e suscite o seu relato. A estrutura prototípica da confidência desenvolve-se em três etapas: a abertura, em que o narrador apresenta o tema da sua confissão; a exposição: transparência enunciativa e emergência da partilha sigilosa; e a conclusão.

Como referimos nos pontos anteriores, os factos enunciados decorrem de estados de alma do narrador, desencadeados a partir de um acontecimento ou de

\footnotetext{
15 ROCHA, p. 28.

16 DIDIER., p. 59.

17 DIDIER, p. 88.

18 DIDIER, p. 154.
} 
Linha D'Água (Online), São Paulo, v. 31, n. 1, p. 73-89, jan.-abril 2018

uma situação que despoletou esse estado, de ordem afectivo. Uma das funções primordiais da confidência é a necessidade de partilhar a carga emocional de determinados acontecimentos. A confidência exprime, assim, uma situação particular de evocação de emoções: o confidente expõe a sua face conduzindo o outro a zonas do seu território supostamente protegidas e privadas. Por outro lado, a confidência pressupõe que haja um postulado de empatia na partilha das emoções.

Deter-nos-emos na análise pragmática de três mecanismos que configuram este acto da confidência:

4.1 Marcadores de precaução ou de confidencialidade (Liana Pop 2007): iniciativos ou conclusivos ("é absolutamente confidencial”; "por favor, não contes a ninguém”, “fica entre nós”)

4.2 Elementos configuradores: marcas do eu - explicitação dos sentimentos na primeira pessoa; os apelativos diversos de apoio no outro ("tu sabes bem");

4.3 Sequências confessionais: as hesitações explícitas, a procura das palavras certas, os silêncios.

\section{Análise de alguns exemplos}

Analisamos em alguns textos, representativos de várias modalidades de escrita intimista (diário, carta de amor, blogue, etc.) essas especificidades.

Atente-se nesta crónica de António Lobo Antunes, uma das suas crónicas autobiográficas, em que escreve, em jeito epistolar, qual elogio fúnebre, um texto à sua cunhada, Margarida Vieira Mendes:

(...) e nisto o pai levantou-se com a brusquidão do costume, ouviram-se os passos dele nas escadas e ao descer mostrou-me sem uma palavra uma dedicatória tua num livro em que dizias que gostavas muito dele: espantei-me transgredires uma das nossas regras que é a de gostar sem nos referirmos a isso, por pudor, por descrição, porque não é preciso. O enterro foi no sábado. Levei o pai e o azul dos olhos dele (igual ao azul dos olhos de nós todos)

Impressionou-me.

Não me lembro o escritor que discutimos (imagino o teu sorriso ao leres isto) e todavia lembro-me de querer ficar para trás e de o Miguel me chamar. 
Linha D'Água (Online), São Paulo, v. 31, n. 1, p. 73-89, jan.-abril 2018

(...)

E como ias à frente não me viste chorar.

(...) mesmo que não mostre, e faço os possíveis por não mostrar, tenho saudades de te ouvir.

Que gaita de coisa ter tantas saudades de te ouvir" ${ }^{19}$

Nas cartas de amor, depois de fazer confidências e revelar segredos, aparece este fecho:

"Desculpa este longo discurso. Tenho a impressão de que fui maçador de mais com este longo estendal do meu ego... Mas só a ti conto estas coisas, porque és a coisa mais preciosa que tenho no mundo. Guarda segredo.

Amo-te

António ${ }^{20}$

Atentemos, ainda, em alguns exemplos de blogues, em que explicitamente se denuncia esta vontade confessional (através da forma verbal "confesso") e em que se partilham, as emoções sentidas, envolvendo através desta expressão clara de sentimentos, o leitor na comunhão de reflexões pessoais.

Realce-se, porém, que a mediação do ecrã permite uma verdadeira desinibição, na medida em que o autor, tendo menos consciência da presença do outro, confessa-se com mais facilidade, corroborando assim a reflexão de Aupeix: "Nous percevons donc dans la pratique du journal intime en ligne l'épanouissement d'une démarche personnelle, mais également un désir de partager". (Aupeix 2000: 55)

Como sublinha Pop 2008, estamos em presença de "marqueurs explicites (méta-commentaires) qui sont "en tout premier lieu les noms dont les langues naturelles désignent les opérations discursives de type confidence / dévoilement du soi, notamment des verbes comme confier, avouer, témoigner, révéler, dévoiler, dire la vérité".

19 ANTUNES, 2002, p. 351-353.

20 ANTUNES, 2005, p. 203. 
Linha D'Água (Online), São Paulo, v. 31, n. 1, p. 73-89, jan.-abril 2018

\section{Exemplo 1}

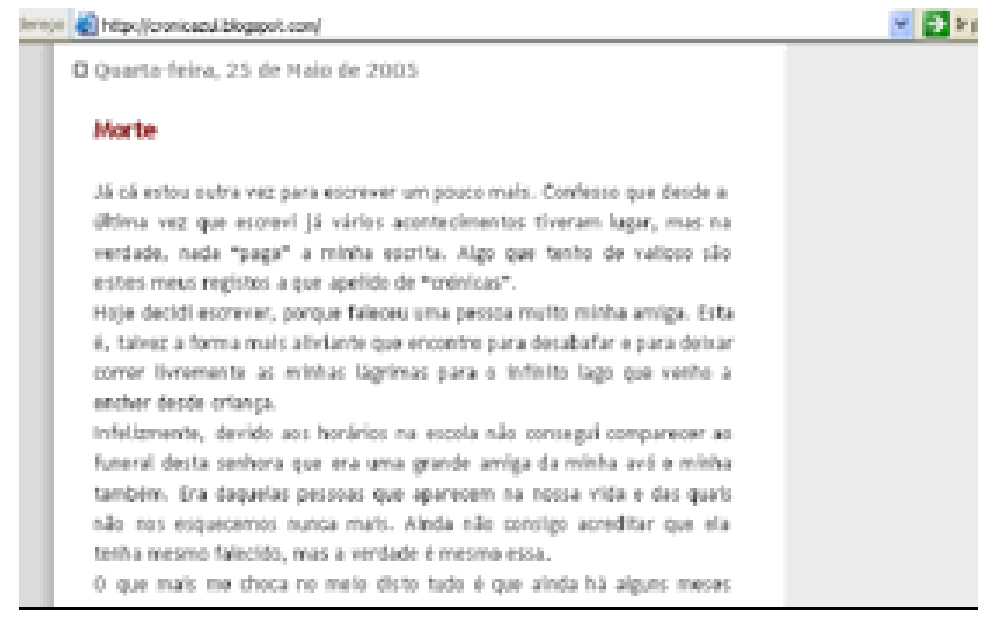

\section{Exemplo 2}

\section{Confesso-me.}

Näo que tenha cometido um qualquer pecado novo, mas apenas porque, num animado jantar de amigos, veio à baila confessar ambiçces. Cada um tinha a sua: comprar um "porsche", ter um determinado "rolex", năo ter que ter emprego e criar cinco filhos, ter uma bruta moradia de vidro virada para o mar, montar um negócio com lucros chorudos... e eu caladinha a pensar na natureza das minhas ambiçôes. Tenho-as, claro que sim, mas são de outro género, năo concretiziveis pelo dinheiro, nåo dependentes dele. Terei levado demasiado tempo a pensar nisso ou melhor, a construir a formulaçåo correcta, que năo me fizesse passar por palerma, que fugisse de lugares comuns do género paz e amor e acabar com a miséria no mundo. Sim, é verdade, os objectivos de grande parte das pessoas passa por ter dinheliro, năo para fazer obra grandiosa que não seja construir o seu próprio bem-estar; daí o 
Linha D'Água (Online), São Paulo, v. 31, n. 1, p. 73-89, jan.-abril 2018

\section{Exemplo 3}

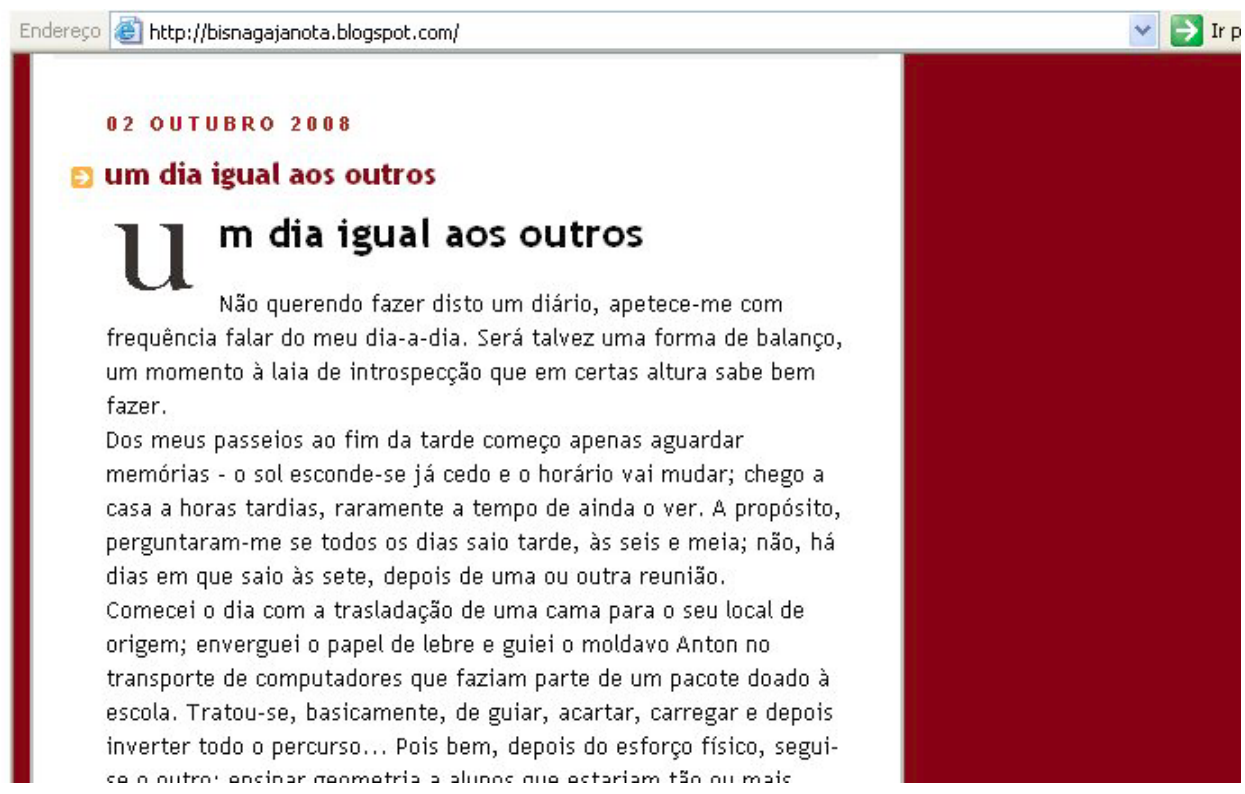

Há contudo marcadores implícitos e estratégias que, como sublinha POP (2008) "invoquent une particularité ou une autre de ce type discursif (sentiments, passage du secret à la vérité, appui sur l'autre, précautions à prendre, etc.) et indiquant par là, de façon métonymique, le type de discours qu'on veut produire ou de contrat qu'on veut imposer".

Numa análise mais detalhada dos exemplos, podemos encontrar diferentes tipos de marcadores que optámos por classificar segundo a tipologia de POP 2008. Assim, estamos em presença de:

1. marcadores de sinceridade, em que se explicita o refúgio na escrita em momentos de angústia e desespero: "Esta é talvez a forma mais aliviante que encontro para desabafar e para deixar correr livremente as minhas lágrimas" (exemplo 1), evidenciando-se assim a autenticidade que subjaz ao ato da escrita confessional, mesmo em suporte eletrónico e que confirma a afirmação lapidary de Zimbrano: "La confession a lle aussi un commencement désespéré" (2007: 37). 
Linha D'Água (Online), São Paulo, v. 31, n. 1, p. 73-89, jan.-abril 2018

Atente-se na expressão "sim, é verdade" (exemplo 1) que visa reforçar a dimensão da sinceridade da escrita autobiográfica.

2. marcadores de precaução ou confidencialidade que impõem o sigilo, bem patente, desde logo, na escolha do título do exemplo 2, em que o autor enuncia simplesmente o seu ato confessional pela forma verbal pronominal "Confesso-me”, para posteriormente dissertar e confessar as suas ambições, num discurso marcado pela presença reiterada de marcas de 'eu'.

É inquestionável que um dos traços mais marcantes dos diários íntimos é o facto de serem, normalmente, escritos apenas para si e mantidos guardados em segredo. A lógica estrutural do blogue confessional, ao contrário, é a de ser escrito no formato de posts e publicado periodicamente para ser lido. Os blogues confessionais, criados como páginas na internet, já surgem supondo a exibição da escrita íntima na rede e a existência de um público leitor.

L'intérêt d'un corpus de journaux personnels en ligne pour le propos de cet article réside dans le paradoxe qui sous-tend le projet d'écriture de soi sur un média informatisé et, qui plus est en réseau, alors que la tenue d'un journal est réputée privée et autarcique. Certes, le journal commence par s'auto-destiner parce que le diariste écrit avant tout pour lui. Cependant, l'étude de divers journaux personnels révèle qu'en creux de cette « auto-communication » qui en fonde le geste, et quel qu'en soit le support (cahier, feuilles, carnet, Web...), le journal comporte un appel à l'autre. Deseilligny, 2006: 22.

\section{Dialogismo na escrita intimista}

Esta vanitas da escrita intimista é, todavia, denunciada através das marcas enunciativas, fundamentalmente dialógicas, embora, como mostrámos anteriormente, o regime enunciativo da escrita seja monológico. Desta forma, longe de ser um refúgio do sujeito individual, torna-se num lugar de experiência em que o destinatário é parte constitutiva dessa figuração do 'eu'.

Não são manifestamente textos sem destinatário, como é demonstrado por Rousset ao postular que existe sempre um leitor íntimo. Nesse mesmo sentido, 
Linha D'Água (Online), São Paulo, v. 31, n. 1, p. 73-89, jan.-abril 2018

Mireille Calle-Gruber releva as formas de ritualização, frisando que a figura do destinatário está sempre presente, seja na forma de um 'eu' desdobrado, seja na forma do próprio escrito que é tematizado (exemplo canónico é a expressão de abertura dos diários : « meu querido diário »), seja, ainda na pessoa de um destinatário imaginário que indicia esse âmago ficcional da própria escrita (lembremos, a este propósito, o caso de Kitty, no diário de Anne Frank), seja, por fim, um destinatário externo, elevado a essa categoria privilegiada pela sua proximidade com o autor .

Neste sentido, julgamos importante focalizarmo-nos na dimensão discursiva destas confidências a que correspondem índices de alocução que procedem de uma retórica do endereçamento ao outro, putativo leitor, pelo que um terceiro tipo de marcadores se anuncia:

3. Marcadores de alocução - As formas de tratamento e as expressões fáticas, que são apanágio deste tipo de discurso diarístico, podem ser interpretadas como sinais do desejo de estabelecer um contato direto com o leitor ou, pelo menos de construir, um ambiente comunicacional mais interativo.

Como sublinha Deseilligny: "l'insertion de appellatifs, des adresses désignatives a donc pour effet de convoquer explicitement le lecteur sur la scène d' énonciation, et partant, d'en faire un allocutaire direct du diariste. En outre, ils relèvent d'une forme de deixis par laquelle le sujet d'énonciation se positionne personnellement et socialement (notamment en tant que diariste) vis-à-vis des lecteurs et clarifie les conditions intersubjectives de la communication. (Deseilligny 2006: 22)

\section{Reflexões finais}

A escrita íntima está hoje amplamente disseminada. Escrever sobre si é frequentemente justificar o seu destino, dar um sentido às experiências vividas.

Papel de carta, folha de diário, ecrã de computador, qualquer que seja o suporte e a situação de enunciação, os discursos mantêm-se muito próximos. A meditação do diarista pode ceder o lugar ao diálogo do epistológrafo ou à exibição no blogue. Se o protocolo de alguns tipos de escrita íntima exige uma escrita míope 
Linha D'Água (Online), São Paulo, v. 31, n. 1, p. 73-89, jan.-abril 2018

em que o presente da escrita quase coincide com o presente da experiência, o protocolo autobiográfico, epistolar e das memórias pressupõe uma assimetria na temporalidade que permite outra reflexão.

Esta vaga de escrita intimista, esta obstinação em expor-se, que, no contexto volátil das produções textuais na Internet, amplia a secular tradição confessional revela um "eu" que aparece como único valor absoluto, relicário da intimidade, e que é denominado pelo sociólogo Sennet como personalidade-refúgio, na qual se desenha a recente "tirania da intimidade" ${ }^{21}$. Corroboramos a reflexão do autor que sentenciosamente conclui: «Le moi de chaque individu est devenu son principal fardeau. Se connaître soi-mame est devenu un but, une fin en soi, au lieu d'être un moyen de connaitre le monde».22

\section{Referências}

ALLAM, Malik, Journaux intimes. Une sociologie de l'écriture personnelle. Paris, Harmattan, 1996.

ANTUNES, António Lobo. Livro de crónicas. Lisboa: D. Quixote, 2002.

D'este viver aqui neste papel descripto. Cartas de Guerra. Lisboa : D. Quixote, 2005.

AUPEIX, Anaïs Le journal intime en ligne, entre espace à soi et lieu d'échange. Empan 2009/4 (n. 76), p. 51-56.

BARON, Naomi (2005). Always On: Language in an Online and Mobile World. New York: Oxford University Press.

BLANCHOT, Maurice Le livre à venir. Paris: Gallimard, 1986.

BERTRAUX, Daniel. Les Récits de vie. Paris : Nathan Université, 1997.

21 Richard Sennett, Les Tyrannies de l'intimité, Paris, Seuil, 1979 (The Fall of Public Man, New York, W. W. Norton \& Company 1974).

22 Ibidem, p. 12 
Linha D'Água (Online), São Paulo, v. 31, n. 1, p. 73-89, jan.-abril 2018

CLERC, Thomas. Les écritis personnels. Paris: Hachette Supérieur, 2001.

DESEILLIGNY, Oriane. Les marqueurs communicationnels dans les journaux personnels en ligne. In: Communication et langages. n. 150, 2006. p. 17-33. Disponível em: <http://www.persee.fr/web/revues/home/prescript/article/colan_0336-1500_2006_num_150_1_5354>. Acesso em: 20 ago. 2017

DIDIER, Béatrice. Le journal intime. Paris: Presses Universitaires de France, 1991.

GIRARD, Alain. "Évolution sociale et naissance de l'intime”, in Intime, intimité et intimisme. Colloque de l'Université de Lille, Lille : Éditions Universitaires, 1976.

GOULET, Alain. "Avant-propos”. ELSENEUR n. 14 L'écriture de soi comme dialogue, Caen: Presses Universitaires de Caen, p. 7-10, 1998.

GUSDORF, Georges. Auto-bio-graphie. Paris : Odile Jacob, 1991.

HUBIER, Sébastien. Littératures intimes. Les expressions du moi, de l'autobiographie à l'autofiction. Paris: Armand Coin, 2003.

KAUFMANN, Jean-Claude. L'invention de soi. Une théorie de l'identité, Paris: Armand Colin, 2004.

LEJEUNE, Philippe. Signes de vie. le Pacte autobiographique 2, Paris, Seuil, 2005.

MONTEIRO, Maria da Assunção Morais. A escrita diarística portuguesa no século XX. Centro de Estudos da Universidade de Trás-os-Montes e Alto Douro, 2006.

PACHET, Pierre. Les baromètres de l'âme. Naissance du journal intime. Paris: Hatier, 1990.

PAIS, Ana, O discurso da cumplicidade. Lisboa: Edições Colibri, 2004.

POP, Liana. « La confidence: genres, marqueurs, stratégies et niveaux de textualisation». In : KERBRAT-ORECCHIONI, C. ; TRAVERSO (Org.) Confidence / Dévoilement de soi dans l'interaction, Tübingen: Max Niemeyer, 2007, p. 407-426.

REIS, Carlos; LOPES, Ana Cristina Macário. Dicionário de narratologia. Coimbra: Almedina, 4ª edição revista e aumentada, 1994. 
Linha D'Água (Online), São Paulo, v. 31, n. 1, p. 73-89, jan.-abril 2018

ROCHA, Clara. Máscaras de Narciso: Estudos sobre a literatura autobiográfica em Portugal. Coimbra: Almedina, 1992.

SENNET, Richard. Les Tyrannies de l'intimité, Paris, Seuil, 1979.

SIBILA, P. O show do eu. A intimidade como espetáculo. Rio de Janeiro: Nova Fronteira, 2008.

SIMONTE-TENANT, Françoise. Le journal intime. Genre littéraire et écriture ordinaire. Paris: Téraèdre, 2004.

VELKOVSKA, J. L'intimité anonyme dans les conversations électroniques sur les webchats. Sociologie du travail, n. 44, p. 193-213, 2002.

ZAMBRANO, María. La confession, genre littéraire. Grenoble : Jérôme Millon, 2007.

Recebido : 12/01/2018.

Aprovado : 26/02/2018. 